\title{
Effects of Anti-Juvenile Hormone (Precocene II) Treatment on Phase Changes and Pheromone Production in the Desert Locust, Schistocerca gregaria (Forskal) (Orthoptera: Acrididae)
}

\author{
Amer I. Tawfik ${ }^{1 . *}$, Ellie O. Osir ${ }^{2}$ and Ahmad Hassanali ${ }^{2}$ \\ ${ }^{1}$ Department of Zoology/Entomology, Faculty of Science, Assiut University, Assiut 71516, Egypt; ${ }^{2}$ International Centre \\ of Insect Physiology and Ecology (ICIPE), P.O. Box 30772, Nairobi, Kenya
}

\begin{abstract}
The roles of anti-juvenile hormone (precocene II) on phase changes and pheromone production were examined in laboratory-bred gregarious desert locust, Schistocerca gregaria. Precocene II was applied to last instar nymphs and newly emerged adults in gregarious phase. Generally, the $5^{\text {th }}$ instar nymphs exhibited a higher sensitivity to topical application of precocen II than the adults. In contrast, the adults exhibited a higher sensitivity to injection of precocen II in comparison to $5^{\text {th }}$ instar nymphs. Topical application or injection of precocene II inhibited pheromone production (as measured by the amount of phenylacetonitrile released). Both topical application to $5^{\text {th }}$ instar nymphs and injection to adults affected the external body coloration, sexual behavior and mating of gregarious adult males, S. gregaria in comparison to control insects.
\end{abstract}

Keywords: Anti-juvenile hormone, locust, phase polyphenism, pheromone, precocene, Schistocerca gregaria.

\section{INTRODUCTION}

Locust phase polyphenism is a remarkable form of phenotypic plasticity in which the expression of numerous physiological, morphological and behavioral traits occurs in response to changes in local population density. This polyphenism is continuous and all the intermediate stages are found between the two extreme phases, depending on the direction of the transformation. The gregarious desert locust, $S$. gregaria, is the most destructive international pest, with its distribution extending from India in the east to Africa in the west [1-5]. Therefore, the endogenous factors that regulate the transition from a solitary to a gregarious state and then maintain the gregarious phase are of considerable interest.

The involvement of endocrine factors in the regulation of locust phase transformation has been extensively reviewed [6-11]. It has long been known that the corpora allata (CA) and their product, the juvenile hormone $(\mathrm{JH})$, undeniable affect some phase characteristics and may involve in locust phase change. For example, implantation of extra CA or administration of $\mathrm{JH}$ or $\mathrm{JH}$ analogs, to crowded hoppers induces green color which is considered as a solitary characteristic. This effect was demonstrated in Locusta migratoria $[12,13]$, S. gregaria $[14,15]$, and in other grasshoppers [16]. On the other hand, Joly and Joly [17] and Joly [18, 19] reported that implantation of extra CA into crowded Locusta hoppers results in a decrease of the E/F (length of elytron/length of hind femur) ratio. They even obtained "hypersolitary" values. Also, allatectomy of the gregarious adult

*Address correspondence to this author at the Department of Zoology/Entomology, Faculty of Science, Assiut University, Assiut 71516, Egypt; Tel: +2-088-2333837; Fax: +2-088-2342708;

E-mails: tawfik1@yahoo.com or amertawfik29@gmail.com male resulted in complete absence of the yellow color, but re-implantation of CA or administration of $\mathrm{JH}$ restored yellowing [20, 21].

Previous work on the desert locust, $S$. gregaria, and the African migratory locust, L. migratoria, had implicated a number of pheromonal and interspecific chemical signals in their phase dynamics $[22,23]$. The existence of aggregation pheromone in the air surrounding gregarious $S$. gregaria has been shown in behavioral experiments $[24,25]$. ObengOfori et al. [24] revealed the presence of two aggregation pheromone complexes analyzing volatiles from the faeces as well as from the air surrounding second- to fifth-instar nymphs and adults. Thereafter, Torto et al. [25] identified six electrophysiologically active components in the volatiles of sexually mature male $S$. gregaria: anisole, veratrole, benzaldeyde, guaiacol, phenylacetonitrile and phenol. Phenylacetonitrile was the dominant component, consisting of 80 $\%$ of emission of the older and mature males. In spite of this important result concerning the identification of the aggregation pheromone systems in the desert locust, little is known about the interaction between pheromones and hormones in phase dynamics of the desert locust, S. gregaria.

So far, seven juvenile hormones [MF(Methyl farnesoate), JH 0, JH I, 4-methyl-JH I, JH II, JH III and JHB3] have been identified in insects [26, 27]. They differ in the number of methyl groups. Results by Baehr et al. [28] showed that the hemolymph of L. migratoria contained JH I, II and III. Also, Fuzeau-Braech et al. [29] reported JH I and JH II in L. migratoria. However, when more reliable physicochemical analyses were employed, both Schistocerca and Locusta had exclusively JH III, and no JH I or JH II can be detected [30$32]$, or in other orthopteroid insects [33, 34]. Most insect species contain only JH III. JH 0 , JH I, and JH II are generally confined to Lepidoptera. The form JHB3 first isolated 
from Drosophila and thereafter, has been found in other dipterans and ticks. Methyl farnesoate (MF), which is JH III lacking the epoxide group, has been isolated from some insects and crustaceans, where it may serve as the active $\mathrm{JH}$. On the other hand, Bowers et al. [35] reported that certain chromene derivatives from the plant Ageratum houstonianum induce symptoms of JH-deficiency in the large milkweed bug, Oncopeltus fasciatus as well as in acridids and other Hemipteran species. These authors termed the active substances precocene I (PI) and precocene II (PII). In many insect species precocene (I or II) can act as a JH antagonists [35-37]. Thus, in the present study P II has been used as antijuvenile hormone.

The effects of shifting $S$. gregaria adult members of a solitary-reared colony to crowd-rearing conditions and viceversa were monitored by $\mathrm{GC}$ analyses of the pheromone emission from the males [38, 39]. Crowding of solitarious insects resulted in the production of the pheromone within days. Interestingly, even pairing of two solitarious insects led to detectable production of the pheromone [38]. Aggregation-maturation titer, therefore, could provide a more sensitive measure in monitoring phase changes in desert locust [38]. On the other hand, in locusts, pheromone communication may be regulated by the neuroendocrine system $[9,11]$. Thus, hormones may regulate the biosynthesis and /or release of the pheromone. Nevertheless, no attempt has been made to investigate the effects of exogenous anti-hormones on the pheromone production of the desert locust. Therefore, the objective of the experiments described in the present paper was to examine in more details the effects of exogenous anti-JH (P II) on the phase changes (external coloration and sexual behavior and mating) and pheromone production of the gregarious desert locust, $S$. gregaria.

\section{MATERIALS AND METHODS}

\subsection{Insects}

Locusts, Schistocerca gregaria (Forskal) reared at the International Center of Insect Physiology and Ecology (ICIPE) insectary originating from a stock obtained from the Desert Locust Control Organization for Eastern Africa (DLCO-EA) in Addis Ababa, Ethiopia, were used during the study. The gregarious locusts were reared under crowded conditions in groups of 300-400 individuals in $50 \times 50 \times 50 \mathrm{~cm}$ aluminum cages. Locusts had been reared for more than 70 generation on a diet of grass and wheat bran at $32 \pm 2^{\circ} \mathrm{C}, 60 \%$ relative humidity and $12 \mathrm{~h}$ photoperiod. Newly emerged adult insects (1-2 days old) and $5^{\text {th }}$ instar nymphs (3-5 days old) from the same batch were used in all experiments to eliminate possible variability in physiological status. For each experiment, gregarious males and females in groups of 30 individuals were used under crowded conditions in $20 \times 20 \times 20 \mathrm{~cm}$ aluminum cages in another room under the same conditions as described above.

\subsection{Treatments}

Precocene II (Sigma Chemical Company, U. K.) was dissolved in different concentrations in AnalaR grade acetone for topical applications or in pure olive oil for injections. In topical applications, $5^{\text {th }}$ instar nymphs (3-5 days old) or adults (1-2 days old) received a single dose of $50 \mu \mathrm{g}$ or 150 $\mu \mathrm{g}$ of precocene II (P II) in $5 \mu 1$ acetone on the dorsal side of the abdomen. Another group of nymphs and adults received three consecutive topical applications, each of $50 \mu \mathrm{g}$ (a cumulative of $150 \mu \mathrm{g}$ ) of P II per insect. In this case insects were administered daily for three days on the $3^{\text {rd }}, 4^{\text {th }}$ and $5^{\text {th }}$ days of the $5^{\text {th }}$ instar nymphs or the adults. Control insects received $5 \mu 1$ acetone in a single dose or triple doses. In another experiment, $5 \mu \mathrm{l}$ of olive oil containing $50 \mu \mathrm{g}$ or 150 $\mu \mathrm{g}$ of P II were injected between the second and third sternites on the $4^{\text {th }}$ day of the $5^{\text {th }}$ instar nymphs and adults. A cumulative dose of $150 \mu \mathrm{g}(3 \times 50 \mu \mathrm{g})$ of P II per insect were injected daily for three days as described above. Control insects received only $5 \mu \mathrm{l}$ olive oil also in a single dose or triple doses.

\subsection{Collection and Analyses of Volatiles}

The collection and analyses of volatiles were carried out as described [25]. For each treatment, aeration were carried out on groups of three adult males selected randomly and contained in a trapping chamber $(10 \mathrm{~cm}$ long x $3.5 \mathrm{~cm}$-i.d.) and through a charcoal $(120 \mathrm{mg})$ packed between two glass wool plugs in glass tube $(6 \mathrm{~cm}$ long $\times 8 \mathrm{~mm}$ i.d. $)$ at 106 $\mathrm{ml} / \mathrm{min}^{-1}$ for $18 \mathrm{~h}$ at $32 \pm 2^{\circ} \mathrm{C}$. Collections were replicated three times. The charcoal was eluted with HPLC grade dichloroethan and preserved at $-15^{\circ} \mathrm{C}$. Prior to analysis, each sample was concentrated to $100 \mu 1$ and $250 \mu$ g of $o$-methyl acetophenone was added as an internal standard. Aliquots $(2.5 \mu 1)$ of the extracts were analyzed by capillary gas chromatography (GC) on a Hewlett-Packad (HP) 5890 series II gas chromatograph equipped with a flame ionization detector (FID) and a HP capillary column (Carbowax $20 \mathrm{M}, 50 \mathrm{~m} \mathrm{x}$ $0.32 \mathrm{~mm}$ ID $\times 0.3 \mu \mathrm{m}$ ) using nitrogen as the carrier gas at flow rate of $0.35 \mathrm{ml} / \mathrm{min}^{-1}$. The oven temperature was initially isothermal at $60^{\circ} \mathrm{C}$ for $10 \mathrm{~min}$, then programmed at $5^{\circ} \mathrm{C} / \mathrm{min}^{-1}$ to $180^{\circ} \mathrm{C}$, where it was maintained for $5 \mathrm{~min}$ and then to $220^{\circ} \mathrm{C}$ at $10^{\circ} \mathrm{C} / \mathrm{min}^{-1}$ to where it was maintained for 15 min. Chromatographic peaks were integrated using a HP 3393 Series II integrator.

\subsection{Observations on the External Coloration (Body Yel- low Color), Male Sexual Behavior and Mating}

Observations on the external coloration (body yellow color), male sexual behavior and mating were carried out during the adult stage, four times a day for treated and control insects.

\subsection{Statistical Analysis}

The results were analyzed by ANOVA and Least Significant Difference test (LSD) at $\mathrm{P}<0.05$ using Statistical Analysis System (SAS) [40].

\section{RESULTS}

\subsection{The Effects of Topical Application of P II}

Topical application of a single dose of $50 \mu \mathrm{g}$ of P II to young adults (4 days old) was ineffective $(\mathrm{P}>0.7)$ on pheromone production; the onset and quantity of pheromone release were similar to that of the controls. However, topical application of a cumulative dose of $150 \mu \mathrm{g}$ per insect $(3 \times 50$ $\mu \mathrm{g}$ ) on days 3,4 , and 5 after adult emergence, resulted in a 
slight effect on the maximum amount of pheromone production $(\mathrm{P}>0.3)$. Moreover, there was no significant difference $(\mathrm{P}>0.7)$ on the onset of pheromone production between treated and control insects (Fig. 1). In this case, the pheromone production started on day 15 and reached a maximum 20 days after adult emergence (Fig. 1). Generally, topical application of a single dose of $50 \mu \mathrm{g}$ of P II on day 4 or a cumulative dose of $150 \mu \mathrm{g}$ per insect $(3 \times 50 \mu \mathrm{g})$ on days 3 , 4 , and 5 after adult emergence, had no effect on external yellow coloration, sexual behavior and mating in comparison to control insects.

Topical application of a single dose of $50 \mu \mathrm{g}$ of P II to $5^{\text {th }}$ instar nymphs (4 days old) was ineffective $(P>0.7)$ on pheromone production in the subsequent adult males; the onset and quantity of PAN release were similar to that of control insects (Fig. 2). In contrast, a significant effect $(\mathrm{P}<0.01)$ was observed in insects treated with a cumulative dose of $150 \mu \mathrm{g}$ P II $(3 \times 50 \mu \mathrm{g})$ on days 3,4 , and 5 of $5^{\text {th }}$ instar nymphs. In this case, pheromone production started on day 20 and reached a maximum 35 days after adult emergence (Fig. 2). Also, treated males had a fading yellow color instead of the bright yellow color characteristic of normal gregarious adult males. Moreover, they started exhibiting sexual behavior and mating between 25-30 days instead of 15-20 days after adult emergence in control insects. Generally, topical application of a single high dose of $150 \mu \mathrm{g}$ of $\mathrm{P}$ II on day 4 to $5^{\text {th }}$ instar hoppers or adults had no effect on the onset and quantity of PAN release in comparison to controls.

\subsection{The Effects of Injection of P II}

Injection of a single dose of 50 or $150 \mu \mathrm{g}$ of P II into day 4 adults had no effect on the quantity and onset of pheromone emission (Fig. 3). On the other hand, adults injected with a cumulative dose of $150 \mu \mathrm{g}$ P II $(3 \times 50 \mu \mathrm{g})$ on days 3 , 4 , and 5 started pheromone emission on day $18(\mathrm{P}<0.1)$ and reached a maximum on day $25(\mathrm{P}<0.001)$ (Fig. 3). In addition, treated males had a fading yellow color instead of the bright yellow color characteristic of normal gregarious adult males. Moreover, they started exhibiting sexual behavior and mating between 20-25 days instead of 15-20 days after adult emergence in control insects.

Injection of a single dose of $50 \mu \mathrm{g}$ of P II into $5^{\text {th }}$ instar nymphs (day 4) had no significant effect $(\mathrm{P}>0.7)$ on the onset or quantity of pheromone released in the adult stage (Fig. 4). Also, injection of a single dose of $50 \mu \mathrm{g}$ of P II to $5^{\text {th }}$ instar nymphs (4 days old) had no effect on external yellow coloration, sexual behavior and mating in the adult stage in comparison to control insects. On the other hand, high mortality and deformed adults resulted from a cumulative dose of $150 \mu \mathrm{g}$ P II ( 3 x $50 \mu \mathrm{g})$ or a single high dose $150 \mu \mathrm{g}$. Thus, pheromone production by insects treated with these doses is not shown in Fig. (4).

\section{DISCUSSION}

Color differences between gregarious and solitarious locusts are probably the best known and most easily recognized visible phase characteristic [41, 42]. In crowded $S$. gregaria newly fledged adults are pinkish. Thereafter, the color changes are sex-dependent. With sexual maturation of crowded males, the color changes to yellow, then to bright yellow. In crowded females, the color changes from beigebrown to yellowish, but never becomes bright yellow. Isolated adults of $S$. gregaria do not show appreciable color changes; both sexes are usually beige-brown. Our results showed that topical application to $5^{\text {th }}$ instar nymphs or injection to adults of anti- JH (P II) result in the fading of the yellow color of crowded adult males, $S$. gregaria. The yellowing of crowded adult locusts depends completely on the CA and $\mathrm{JH}$. Allatectomy of young adults or last instar hoppers prevents yellowing, whereas reimplantation of CA or administration of $\mathrm{JH}$ reinduces it in $S$. gregaria [20, 21, 43], $L$. migratoria [44, 45] and Nomadacris sepemfasciata [46]. Moreover, Fridman-Cohen et al. [47] demonstrated that the anti-allatin effect of P II applied to last instar nymphs of

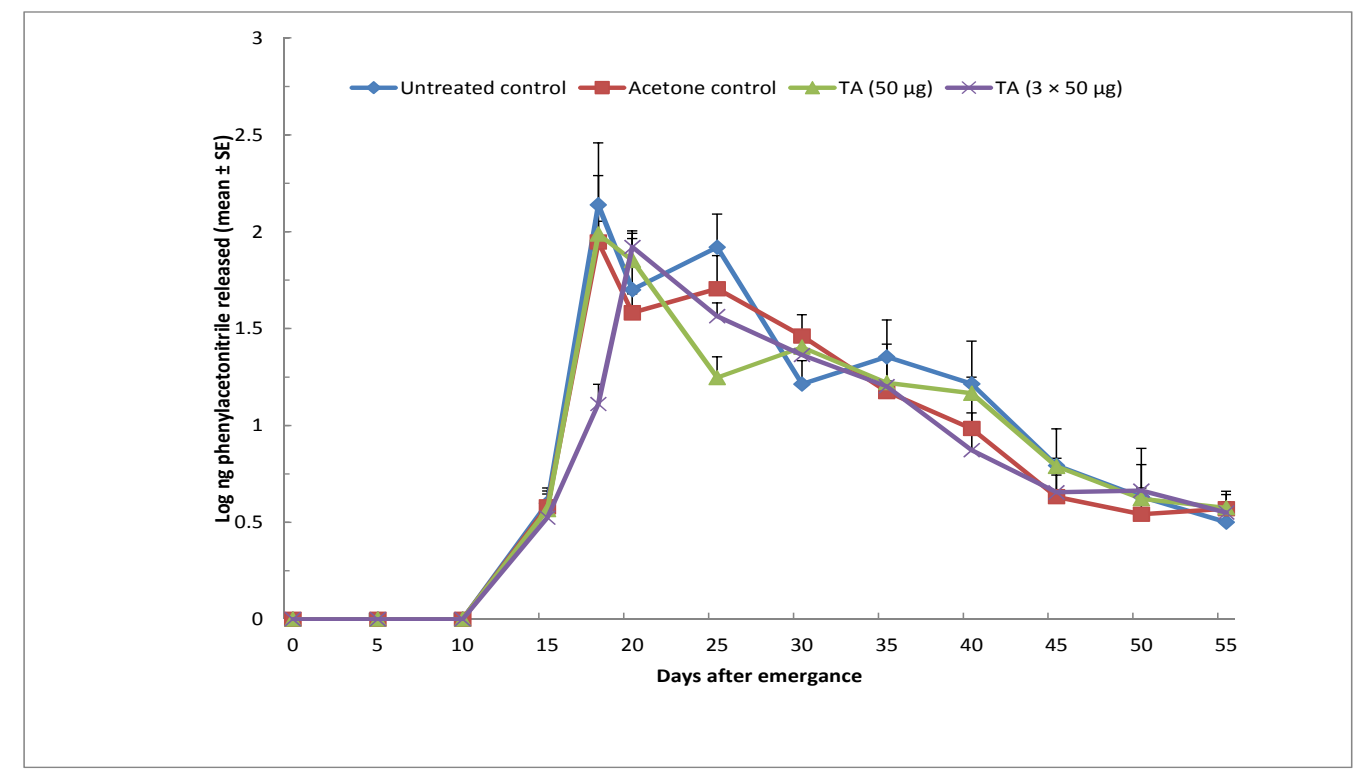

Fig. (1). Release of phenylacetonitrile (mean $\pm \mathrm{SE}$ ) at different ages by adult males, when adults were received topical applications (TA) of precocene II (P II). 


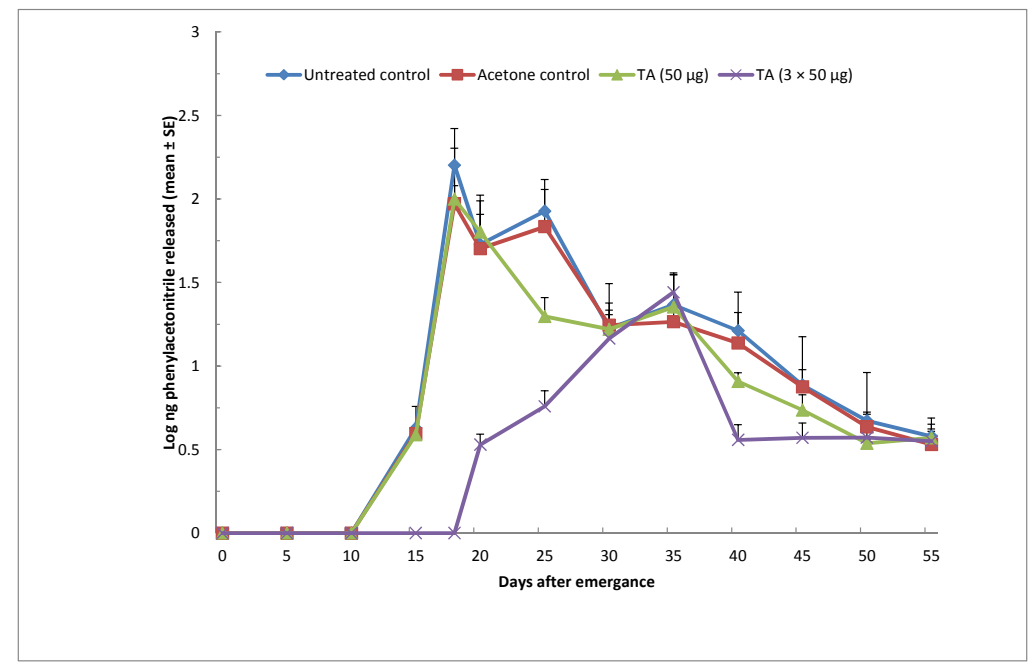

Fig. (2). Release of phenylacetonitrile (mean $\pm \mathrm{SE}$ ) at different ages by adult males, when $5^{\text {th }}$ instar nymphs were received topical applications (TA) of precocene II (P II).

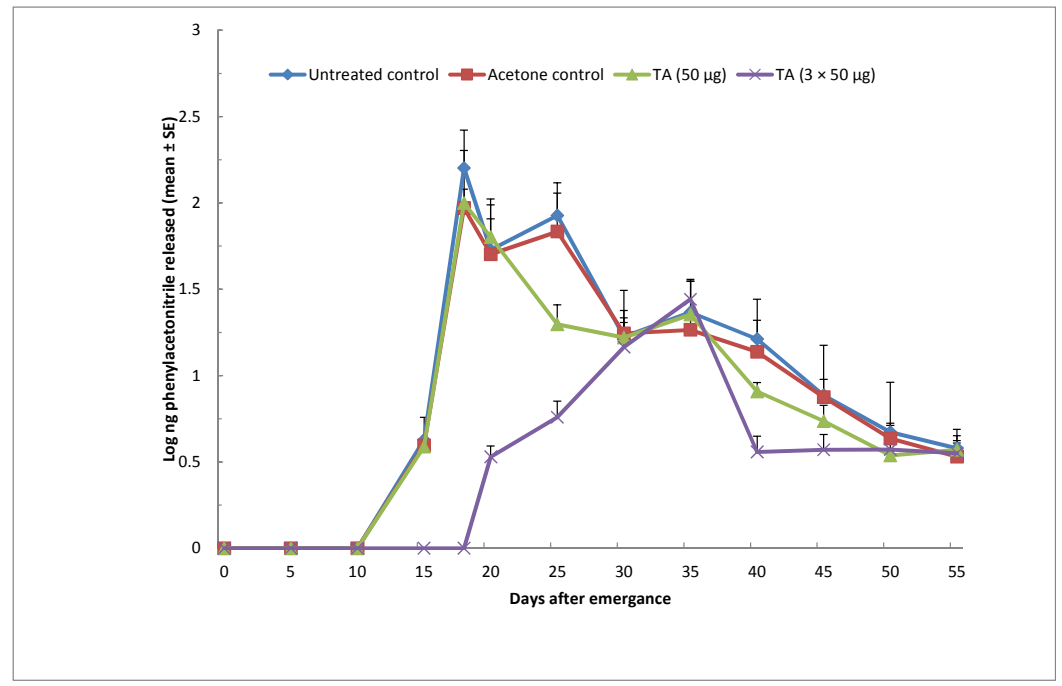

Fig. (3). Release of phenylacetonitrile (mean \pm SE) at different ages by adult males, when adults were injected (Inj.) with different concentrations of precocene II (P II).

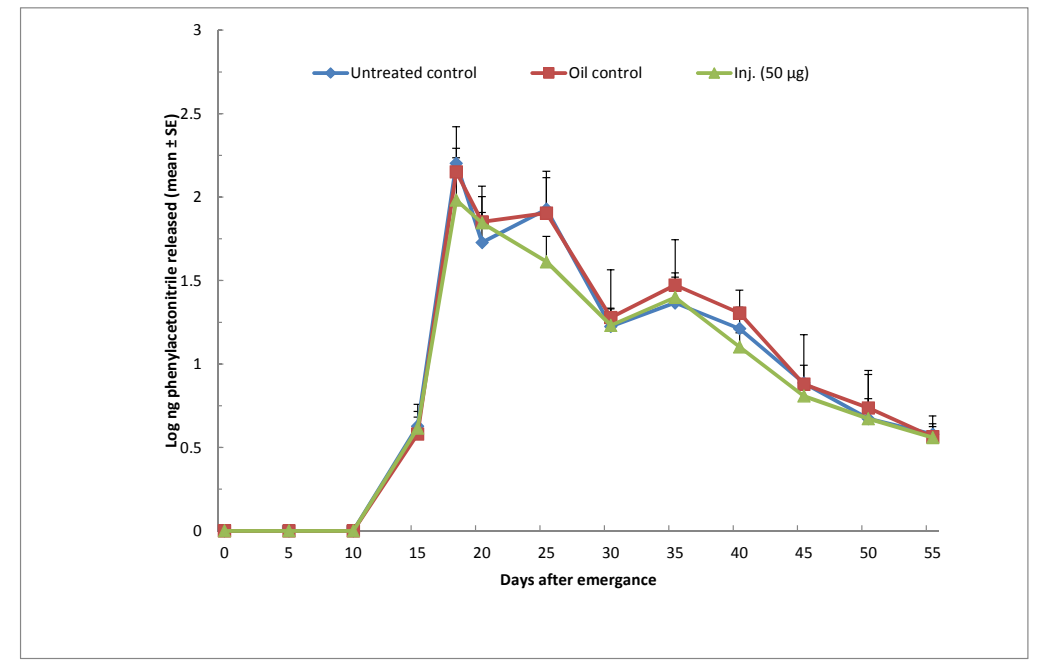

Fig. (4). Release of phenylacetonitrile (mean \pm SE) at different ages by adult males, when $5^{\text {th }}$ instar nymphs were injected (Inj.) with different concentrations of precocene II (P II). 
S. gregaria become overt by sterility and lack of yellow color in the adults. Allatoectomy of sexually mature yellow adults, $S$. gregaria results in the fading of the yellow color [48]. Furthermore, implantation of extra CA into isolated adults does not induce yellowing, whereas transfer of isolated adults into newly formed crowds does, even without implantation of extra CA [45].

The results of the present experiments revealed that maturation, sexual behavior and mating are affected by exogenous anti-JH (P II), and coincided with the pheromone production in gregarious adult males, $S$. gregaria. These results confirmed previous finding that the pheromone has a releaser and primer effects $[24,25,49,50]$. The effect of the CA on mating behavior of adult male locusts and grasshoppers has been investigated by several workers. These glands completely control male sexual behavior in the desert locust, $S$. gregaria $[43,51,52]$, in the migratory locust, L. migratoria [53] and in the red locust, Nomadacris sepemfasciata [46]. However, Norris and Pener [54] reported that the presence of allatectomized males or of allatectomized females inhibit the maturation of young adult males of $S$. gregaria.

Our results showed that anti-JH (P II) plays a role in the regulation of pheromone production in the desert locust, $S$. gregaria. Pheromone production in gregarious adult males, $S$. gregaria was shown to depend on the presence of the CA [20, 43, 54]. Interestingly, Tawfik et al. [32] showed that, the occurrence of maximal CA size (days 7-16) correlates with the onset of emission of the aggregationmaturation pheromone in gregarious adult males, $S$. gregaria. Furthermore, Tawfik and Mohammed [55] showed that at the time of maximal pheromone production the CA cells of gregarious adult male, $S$. gregaria are characterized by thin cytoplasm with only small numbers of mitochondria, smooth endoplasmic reticulum (SER) and ribosomes. Also, the majority of nucleoli were mainly in the form of hollow spheres. Whereas, before and after the maximal pheromone production the CA cells had well developed SER, numerous mitochondria and abundant ribosomes. Also, Odhiambo [56] reported more SER and mitochondria of more complex shapes in CA of adult male, $S$. gregaria developing toward sexual maturity than in those just after adult emergence. In accordance with the previous results, Tawfik et al. [32] found that, the $\mathrm{JH}$ titer in gregarious adult males, $S$. gregaria was low on day 10 , elevated on day 15 coinciding with the start of the production of the pheromone, and dropped to a relatively low level on day 20 around the time of maximal pheromone production, then rising again by day 25 . On the other hand, the effects of juvenile hormone treatment on phase changes and pheromone production in the desert locust, $S$. gregaria were studied [57]. Tawfik et al. [57] administered JH III to 3- to 5-day-old last-instar hoppers and, separately, 3- to 5-day-old young adults of crowded S. gregaria males, by three alternative routes, topical application in acetone, injection in olive oil and exposure to vapor ('fumigation'). The authors recorded significant effect of the treatments on the timing and rate of phenylacetonitrile (PAN) release. Furthermore, Ignell et al. [58] investigated the effect of JH on behavioral patterns of adult $S$. gregaria in response to PAN, which is considered to be the most potent adult aggregation pheromone component in this species [58]. They showed that the behavioral response to the major and most potent adult aggregation pheromone component, PAN, is age- and $\mathrm{JH}$-dependent. In addition, the authors reported that $\mathrm{JH}$ influences the responsiveness of olfactory interneurons in the antennal lobe to aggregation pheromone, whereas the responsiveness of antennal receptor neurons is not changed. Old locusts and locusts injected with $\mathrm{JH}$, in contrast to young locusts and locusts deprived of $\mathrm{JH}$ through allatectomy, do not display any aggregation behavior, as indicated by longterm behavioral observations.

The results of the present study showed that topical application to $5^{\text {th }}$ instar nymphs or injection to adults of anti-JH (P II) inhibits pheromone production in gregarious adult males, S. gregaria. It seems likely that P II influences the pheromone production indirectly by inhibiting $\mathrm{JH}$ production. Topical treatments with P II inhibited the pheromone production in Ips paraconfusus [36]. Precocene II also inhibited or delayed both pheromone production and oocyte growth in a dose-dependent manner in Blattella germanica [37]. However, distinct pheromone glands are not known for male desert locust. It has therefore been assumed that specialized epidermal cells produce such volatiles. This assumption was based on histological studies by [59-61] which describe glandular epidermal cells in the epidermis of mature adult male, $S$. gregaria. Thus, another possible mode of action is that P II could act directly at the site of pheromone production.

Generally, the $5^{\text {th }}$ instar nymphs exhibited a higher sensitivity to topical application of P II than the adults. In contrast, the adults exhibited a higher sensitivity to injection of $\mathrm{P}$ II in comparison to $5^{\text {th }}$ instar nymphs. Treated adults exhibit resistance against topical applications of P II in comparison to last instar nymphs. This could reflect better peripheral protecting mechanism(s) against precocene, such as more efficient metabolic detoxification, higher excretion rate and lower penetration rate through the integument. On the other hand, the $5^{\text {th }}$ instar nymphs exhibited a higher sensitivity to topical applications of P II. From the point of view of the effects of $\mathrm{JH}$ and $\mathrm{JH}$ analogs on the last nymphal instar of both Schistocerca and Locusta may be divided into three distinct intervals $[62,63]$. The first one, ranging from ecdysis to the fourth day of the instar, is the period of the action of $\mathrm{JH}$ on morphogenesis. The second interval, which encompassed days 4 and 5, represents the sensitive period for the phase changes. In the third interval from day 6 to the next ecdysis, JHs induce no visible effect. Further important endocrinological relationships exist between the occurrence of sensitive period to $\mathrm{JH}$ and the titers of ecdysteroids in the body [64]. Moreover, the two phases differ markedly in ecdysteroid titer in the hemolymph during the last two nymphal instars [65].

Several reports have indicated that, in locusts, the gregarious phase is characterized by a lower $\mathrm{JH}$ content than in the solitarious phase [28, 66-68]. Thus, an experimental elevation of the $\mathrm{JH}$ content in gregarious locusts should induce a solitarization. This is in agreement with results by Tawfik et al. [57] that the exogenous JH treatments affect the coloration and timing and rate of PAN release in gregarious adult males of the desert locust. Contrarily, results of the present study showed that JH deficiency caused by anti-JH (P II) affects the pheromone production, coloration, sexual behav- 
ior and mating in gregarious adult males, $S$. gregaria. Moreover, Tawfik et al. [32] found that the pheromone production coincides with a specific titer of $\mathrm{JH}$ in gregarious adult males of the desert locust. Furthermore, as mentioned above the occurrence of maximal CA size (days 7-16) correlates with the onset of emission of the aggregationmaturation pheromone [32]. Also, the ultrastructural study revealed that at the time of maximal pheromone production the CA cells of gregarious adult male, $S$. gregaria contain small number of mitochondria, smooth endoplasmic reticulum (SER) and ribosomes [55]. Whereas, before and after the maximal pheromone production the CA cells had well developed SER, numerous mitochondria and abundant ribosomes. Therefore, phase changes and pheromone production of the desert locust could be regulated by threshold of $\mathrm{JH}$ at a critical period.

\section{CONFLICT OF INTEREST}

The authors confirm that this article content has no conflict of interest.

\section{ACKNOWLEDGEMENTS}

We are grateful to the staff of the locust rearing unit Messrs Ndugo, Ongudha and Nganga for regular supply of insects. This work was supported by funds from a consortium of donors coordinated by International Fund for Agricultural Development (IFAD) through the Consultative Group on Locust Research (CGLR), United Nations Development Program (UNDP), Swedish Agency for Research Cooperation with Developing Countries (SAREC) and Arab Fund for Economic and Social Development (AFESD) to whom we are grateful. Comments and suggestions of two anonymous reviewers are greatly appreciated.

\section{REFERENCES}

[1] Wallsh J. Locust in Africa: A plague is possible. Science 1988; 242: 1627-8.

[2] Skaf R. The development of a new plague of the desert locust Schistocerca gregaria (Forskal) (Orthoptera: Acrididae) 19851989. Bolet Sanidad Vegetal Fuera Ser 1990; 20: 59-66.

[3] Skaf, R, Popov GB, Roffey J. The desert locust: An international challenge. Philos Tran R Soc London 1990; 328B: 525-38.

[4] Showler AT, Potter CS. Synopsis of the 1986-1989 desert locust (Othoptera: Acrididae) plague and the concept of strategic control. Am Entomol 1991; 37, 106-10.

[5] Bell M. The 2004 desert locust outbreak. Bull Am Meteor Soc 2005; 86: S60 (special section on 'State of The Climate in 2004).

[6] Pener MP. Endocrine aspects of phase polymorphism in locust. In: Downer RGH, Laufer H, Eds. Invertebrate Endocrinology Vol. 1, Endocrinology of Insects. Alan R Liss Inc New York 1983; pp. 379-94.

[7] Pener MP. Locust phase polymorphism and its endocrine relations. Adv Insect Physiol 1991; 23: 1-79.

[8] Dale JF, Tobe SS. The endocrine basis of locust phase polymorphism. In: Chapman RF, Joern A, Eds. Biology of Grasshoppers. John Wiley \& Sons: New York 1990; pp. 393-414.

[9] Tawfik AI, Sehnal F. A role for ecdysteroids in the phase polymorphism of the desert locust. Physiol Entomol 2003; 28: 19-24.

[10] Pener MP, Simpson SJ. Locust phase polyphenism: An update. Adv Insect Physiol 2009; 36: 1-286.

[11] Tawfik AI. Hormonal control of the phase polyphenism of the desert locust: A review of current understanding. Open Entomol J 2012; 6: 22-41.

[12] Staal GB. Studies on the physiology of phase induction in L. migratoria (R\&F). H Veenman Zonen N V Wageningen Netherlands 1961.
[13] Couillaud F, Mauchamp B, Girardie A. Biological, radiochemical and physicochemical evidence for the low activity of disconnected corpora allata in locust. J Insect Physiol 1987; 33: 223-8.

[14] Novak VJ, Ellis PE. The metamorphosis hormone and the phase dimorphism in S. gregaria. II. Implantations of the glands into hoppers reared in crowded conditions. Gen Comp Endocr 1967; 9: 477-8.

[15] Langewald J, Schmutterer H. Colour change in the desert locust, $S$. gregaria (Forsk.), induced by topical treatment with azadirachtinenriched neem oil in semi-field trails in Benin at different population densities. J Appl Entomol 1995; 119: 221-6.

[16] Rowell CH. Corpus allatum implantation and green/brown polymorphism in three African grasshoppers. J Insect Physiol 1967; 13: 1401-12.

[17] Joly P, Joly L. Resultals de greffes de corpora allata chez L. migratoria L. Annls Sci nat Zool Ser II 1954; 15: 331-45.

[18] Joly P. Croissance et indices de gregarisation chez L. migratoria (L.). Insectes Soc 1956; 3: 17-24.

[19] Joly P. Role joue par les corpora allata la realisation du polymorphisme de phase chez L. migratoria L. Collo Int CNRS Physiolgie, Comportement et Ecologie des Acridiens en rapport avec la phase 1962; 114: 77-88.

[20] Loher $\mathrm{W}$. The chemical acceleration of the maturation process and its hormonal control in the male of the desert locust. Proc R Soc 1961; 153B: 380-97.

[21] Pener MP, Lazarovici P. Effect of exogenous juvenile hormones on mating behavior and yellow color in allatectomized adult male desert locusts. Physiol Entomol 1979; 4: 251-61.

[22] Nolte DJ. A pheromone for melanization of locusts. Nature 1963; 200: 660-1.

[23] Gillett SD. Airborne factor affecting the grouping behavior of locusts. Nature 1968; 218: 782-3.

[24] Obeng-Ofori D, Torto B, Hassanali A. Evidence for mediation of two releaser pheromones in aggregation behaviour of the gregarious desert locust, Schistocerca gregaria. J Chem Ecol 1993; 19: 1665-76.

[25] Torto B, Obeng-Ofori D, Njagi P, Hassanali A, miani H. Aggregation pheromone system of adult gregarious desert locust, Schistocerca gregaria (Forska.). J Chem Ecol 1994; 20: 1749-62.

[26] Schooley DA, Baker FC, Tsai L, Miller CA, Jamieson GC. Juvenile hormone 0 , I and II exist only in Lepidoptera. In: Hoffmann J, Porchet M, Eds. Biosynthesis, Metabolism and Mode of Action of Invertebrate Hormones. Springer Berlin Heidelberg 1984; pp. 37383.

[27] Goodman WG, Cusson, M. The juvenile hormone. In: Gilbert LI, Ed. Insect Endocrinology. Amsterdam, Boston: Academic Press 2012; pp 310-65.

[28] Baehr JC, Porcheron P, Papillon M, Davy F. Haemolymph levels of juvenile hormone, ecdysteroids and protein during the last two larval instars of L. migratoria. J Insect Physiol 1979; 25: 415-21.

[29] Fuzeau-Braesch S, Nicolas G, Baehr JC, Porcheron P. A study of hormonal levels of the locust L. migratoria cinerascens artificially changed to the solitary state by a chronic $\mathrm{CO}_{2}$ treatment of one minute per day. Comp Biochem Physiol 1982; 71 A: 53-8.

[30] Bergot BJ, Schooley DA, De Kort CAD. Identification of JH III as the principal juvenile hormone in L. migratoria. Experientia 1981; 37: 909-10.

[31] Mauchamp B, Couillaud F, Malosse C. Gas chromatography-mass spectroscopy analysis of juvenile hormone released by insect corpora allata. Ana Biochem 1985; 145: 251-6.

[32] Tawfik AI, Lackner B, Hassanali A, Osir E. Time-course haemolymph juvenile hormone titres in solitarious and gregarious adults of Schistocerca gregaria, and their relation to pheromone emission, CA volumetric changes and oocyte growth. J Insect Physiol 2000; 46: 1143-50.

[33] Loher W, Ruze L, Baker FC, Miller CA, Schooley DA. Identification of the juvenile hormone from cricket, Teleogryllus commadus and juvenile hormone changes. J Insect Physiol 1983; 29: 585-9.

[34] Baker FC, Lanzrein B, Miller CA, Tsai L, Jamieson GC, Schooley DA. Detection of only JH III in several life stages of Nauphoeta cinerea and Themobia domestica. Life Sci 1984; 35: 1553-60.

[35] Bowers W, Ohta T, Cleere JS, Marsella PA. Discovery of insect anti-juvenile hormones in plants. Science New York 1976; 193: 542-7.

[36] Kiehlmann E, Conn JE, Borden JH. 7-Ethoxy-6-methoxy-2,2dimethyl-2H- benzopyran. Org Prep Proc Int 1982; 14: 337-42. 
[37] Schal C, Burns EL, Blomquist GJ. Endocrine regulation of female contact sex pheromone production in the german cockroach, Blattella germanica. Physiol Entomol 1990; 15: 81-91.

[38] Deng AL, Torto B, Hassanali A, Ali EE. Effects of shifting to crowded or solitary conditions on pheromone release and morphometrics of the desert locust, Schistocerca gregaria (Forsk.). J Insect Physiol 1996; 42: 771-6.

[39] Tawfik AI. Effect of isolation or crowding on morphometrics, hemolymph pigments and juvenile hormone titre of the desert locust, Schistocerca gregaria (Orthoptera: Acrididae). Bull Fac Sci Assiut Univ 2004; 33E: 1-10.

[40] SAS/STAT ${ }^{\mathrm{TM}}$ Guide for Personal Computers, version 6. By SAS Institute Inc Cary NC USA 1988.

[41] Norris MS. Sexual maturation in the desert locust (S. gregaria Forskal) with special reference to the effects of grouping. AntiLocust Bull 1954; 18: 1-44.

[42] Pener MP. Effects of allatectomy and sectioning of the nerves of the corpora allata on oocyte growth, male sexual behavior and color change in adults of $S$. gregaria. J Insect Physiol 1967; 13: 665-84.

[43] Amerasinghe FB. Effects of JH I and JH III on yellowing, sexual activity and pheromone production in allatectomized male Schistocerca gregaria. J Insect Physiol 1978; 23: 603-11.

[44] Girardie A, Vogel A. Etude du controle neuro-humoral de l'activite sexuelle male de L. migratoria (L.). C r hebd Seanc Acad Sci Paris 1966; 263D: 543-6.

[45] Pener MP. The differential effect of the corpora allata on yellow colouration in crowded and isolated Locusts migratoria migratotioides (R. \& F) males. Acrida 1976; 5: 269-85.

[46] Pener MP. The effect of corpora allata on sexual behavior and adult diapause in males of the red locust. Entomol Exp Appl 1968; 11: 94-100.

[47] Fridman-Cohen S, Staal GB, Pener MP. Quantitative studies on anti-allatin and lethal effects of a synthetic precocene in different larval instars of the desert locust. Entomol Exp Appl 1984; 36: 11524.

[48] Pener MP. On the influence of corpora allata on maturation and sexual behaviour of Schistocerca gregaria. J Zool 1965; 147; 11936.

[49] Mahamat H, Hassanali A, Odongo H, Torto B, El Bashir S. Studies on the maturation-accelerating pheromone of the desert locust, $S$. gregaria (Orthoptera: Acrididae). Chemoecol 1993; 4: 159-64.

[50] Rono E, Njagi PGN Bashir MO Hassanali A. Concentration dependent parsimonious releaser roles of gregarious male pheromone of the desert locust, Schistocerca gregaria. J. Insect Physiol 2008; 54: $162-8$.

[51] Odhiambo TR. Growth and the hormonal control of sexual maturation in the desert locust, $S$. gregaria (Forskal). Trans R Entomol Soc London 1966; 188: 393-412.

[52] Pener MP, Wajc E. The effect of allatectomy on male sexual behavior in adult S. gregaria and L. migratoria. In: Novak VJA, Slama K, Eds. Insect Endocrines, also as suplementa Acta Ento- mologica Bohemoslovaca. Czechoslovak Academy Sci Prague 1971; pp 39-43.

[53] Wajc E, Pener MP. The effect of the corpora allata on the mating behavior of the male migratory locust, L. migratoria. Israel J Zool 1969; 18: 179-92.

[54] Norris MS, Pener MP. An inhibitory effect of allatectomized males and females on the sexual maturation of young male adults of $S$. gregaria (Forskal). Nature 1965; 208: 1122 .

[55] Tawfik AI, Mohammed M, Ultrastructure of the corpus allatum in the solitary and gregarious adult male, Schistocerca gregaria in relation to pheromone production. Bull Fac Sci Assiut Univ 1997; 1E: $1-18$

[56] Odhiambo, TR. Ultrastructure of the development of the corpus allatum in the adult male of the desert locust. J Insect Physiol 1966; 12: 995-1002.

[57] Tawfik AI, Osir E, Hassanali A, Ismail S. Effects of juvenile hormone treatment on phase changes and pheromone production in the desert locust, Schistocerca gregaria. J Insect Physiol 1997; 43: 1177-82.

[58] Ignell R, Couillaud F, Anton S. Juvenile-hormone-mediated plasticity of aggregation behavior and olfactory processing in adult desert locust. J Exp Biol 2001; 204: 249-59.

[59] Strong L. Epidermis and pheromone production in males of the desert locust. Nature 1970; 228: 285-6.

[60] Strong L. Interacellular ducts in the epidermis of the male desert locust. J Insect Physiol 1971; 17: 1823-31.

[61] Ali Y. Pheromone-secreting cells in the epidermis of L. migratoria migratoriodes. Pakistan J Zool 1987; 19: 127-32.

[62] Fuzeau-Braesch S. Contribution a l'etude de l'homochromle chez $L$ migratoria. Coll Int CNRS 1968; 173: 163-70.

[63] Nemec V, Jarolim V, Hejno K, Sorm F. Natural and synthetic materials with insect hormone activity . 7 Juvenile activity of the farnesane-type compounds on L. migratoria and S. gregaria (Forsk.). Life Sci. (II) 1970; 9: 821-31.

[64] Slama K. Pharmacology of insect juvenile hormones. In: Kerkut GAK, Gilbert LI, Eds. Comprehensive Insect Physiology Biochemistry and Pharmacology Vol.8, Endocrinology II. Pergamon Press Oxford 1985; pp 357-94.

[65] Tawfik AI, Mathová A, Ismail S, Sehnal F. Haemolymph ecdysteroids in the solitary and gregarious larvae of Schistocerca gregaria Arch Insect Biochem Physiol 1995; 31: 427-38.

[66] Joly L, Joly P. Comparaison de la phase gregaire et de la phase solitaire de Locusta migratoria migratorioides (Orthoptere) du point de vue de la teneur de la leneur de leur hemolymphe en hormone juvenile. C R hebd Seanc Acad Sci Paris 1974; 279D: 10079.

[67] Injeyan HS, Tobe SS. Phase polymorphism in Schistocerca gregaria: Assessment of juvenile hormone synthesis in relation to vitellogenesis. J Insect Physiol 1981; 27: 203-10.

[68] Dale JF, Tobe SS. Biosynthesis and titre of juvenile hormone during the first gonotrophic cycle in isolated and crowded L. migratoria females. J Insect Physiol 1986; 32: 763-9.

Received: February 07, 2014
(C) Tawfik et al.; Licensee Bentham Open.

Revised: May 11, 2014

Accepted: May 12, 2014

This is an open access article licensed under the terms of the Creative Commons Attribution Non-Commercial License (http://creativecommons.org/licenses/by-nc/3.0/) which permits unrestricted, non-commercial use, distribution and reproduction in any medium, provided the work is properly cited. 